\title{
Prospective study of large uterine fibroids encountered during laparotomy and hysterectomy and their management
}

\author{
Y. Lakshmi Nalini ${ }^{1}$, A. Sarath Chandra ${ }^{2 *}$, M. Akshitha ${ }^{3}$
}

\begin{abstract}
${ }^{1}$ Department of Obstetrics and Gynecology, ${ }^{2}$ Department of General Surgery, ${ }^{3}$ Department of General Surgery, Malla Reddy Institute of Medical Sciences, Suraram, Quthbullapur, Hyderabad, India
\end{abstract}

Received: 13 August 2018

Accepted: 18 August 2018

\section{*Correspondence:}

Dr. A. Sarath Chandra,

E-mail: allurusarath@gmail.com

Copyright: () the author(s), publisher and licensee Medip Academy. This is an open-access article distributed under the terms of the Creative Commons Attribution Non-Commercial License, which permits unrestricted non-commercial use, distribution, and reproduction in any medium, provided the original work is properly cited.

\section{ABSTRACT}

Background: Study of large fibroids is necessary to throw light on complications associated with them. This helps the surgeon to safeguard patients from anticipated complications during surgery. The objective is to study the clinical features, complications and outcome of large uterine fibroids.

Methods: A hospital based prospective study was carried out among 32 eligible patients undergoing laparotomy hysterectomy at Department of Obstetrics and Gynecology from October 2015 to June 2018. Age groups, clinical features, complications and outcome of surgery were recorded. Data was analyzed using proportions.

Results: Majority of the study subjects were in the age group of 25-35 years. The most common presenting symptom of large size fibroid uterus was abnormal uterine bleeding followed by pain abdomen in $18.8 \%$ of the cases. Majority of the women had fibroid size of 16-20 weeks in $62.5 \%$ of the cases followed by size of the $20-26$ weeks in $31.3 \%$ of the cases. Only two women had very large size of $26-28$ weeks in $6.3 \%$ of the cases. Only three patients had intra operative complications $(9.4 \%)$. Among them two $(6.3 \%)$ had injury to the urinary bladder and only one had injury to the ureters. $90.6 \%$ of the cases had no intra operative complications. All cases had complete symptomatic relief. Thus the successful outcome was seen in $100 \%$ of the cases.

Conclusions: Large uterine fibroids can end up with urological complications more than smaller fibroids. Among these bladder and ureteric complications are important. Malignant degeneration is rare. Other complications include infection and wound dehiscence.

Keywords: Hysterectomy, Laparotomy, Management, Uterine fibroids

\section{INTRODUCTION}

It has been estimated that the prevalence of fibroid uterus is around $5-20 \%$. The most common age group affected is 20-40 years. Smooth muscle cell proliferation result in myomas. The important reason for occurrence of myomas is imbalance in the hormones. They arise from individual myoma cells. Among all the tumors of the female genital tract, the most common tumors are the myomas. They are benign in nature. They are solid in consistency. But they are associated with a lot of discomfort and disturbances like excessive bleeding during menstruation, metrorrhagia, and pain in abdomen which may be referred to the thighs. They can even be a cause of infertility. Large size myomas can press upon urinary bladder and lead to pressure symptoms. Myomas can also cause malignant degeneration, infection or cystic degeneration. Myomas are of three types. They can be sub mucosal, sub serosal, or intra mural. Their location in the uterus is not fixed one. They can be found anywhere inside the uterus. Incidence of ureteric injuries is more in 
case the myomas are located at the cervix and broad ligament. $^{1}$

There are two approaches for removal of fibroids. That can be done either through vagina or abdomen. Hysterectomy using abdominal approach is considered safe due to less incidence of infection, less incidence of thrombosis and less incidence of other complications. For fibroids which are large and diffuse in nature, abdominal approach is preferred over vaginal approach. Even it has been recommended over laparoscopic hysterectomy. In case the findings suggest that there are due to previous surgeries dense adhesions then laparotomy and hysterectomy is recommended. While the surgeon is operating on uterus, it must be kept in mind that if neglected, there can be injuries to the urinary tract. This is due to the fact that the urinary tract and the genital tract are in very close proximity in females. In case an injury occurs, it must be immediately recognized and managed promptly to avoid post-operative complaints from the patients. It has been estimated that the incidence of urinary tract injuries among women undergoing uterine surgery is around $1-2 \%$.

This incidence is said to increase as the size of the fibroid increases. Bladder injury is the most common type of urinary tract injury encountered in such procedures.

When fibroid size is large, located at cervix and is placed on the anterior wall of the uterus then in such cases they are very close to the urinary bladder and chances of urinary bladder injury in removal of these types of fibroids are very high. Hence in such cases it has been advised that the surgeon must do the myomectomy as the first step. This will help the surgeon to have a very clear look at the vault of the vagina and this will prevent the injury to the urinary bladder. For safe hysterectomy, in cases of fibroid which is central and cervical, enucleation of the fibroid is the most recommended procedure. ${ }^{2}$

The most common complications of hysterectomy are bleeding, injury to the urinary tract, infection, wound dehiscence, burst abdomen, adhesions development in the abdomen, pulmonary embolism, and even thrombosis. ${ }^{3}$

For hysterectomy to be performed, the women should be more than 40 years of age, she should be multi parous, or if the fibroid is found to be associated with malignancy, or if she is having severe menorrhagia, or if the size of the fibroid is large enough which warrants surgery. Usually total abdominal hysterectomy is advised.

But in certain cases, like if the woman is having pelvic inflammatory disease, endometriosis etc then subtotal hysterectomy can be performed. In comparisons to large size fibroids, the small size fibroids are associated with less number of complications. It has been advised that for removal of large size fibroids, open laparotomy with hysterectomy should be performed. Present study was carried out to study the clinical features, complications and outcome of large uterine fibroids.

\section{METHODS}

Present study was hospital based prospective study. The study was carried out at Department of Obstetrics and Gynecology, Malla Reddy Institute of Medical Sciences, Suraram, Quthbullapur, Hyderabad. The study was carried out from October 2015 to June 2018. During the study period, 124 cases with myomas were reported out of which 32 cases were enrolled for the present study based on the inclusion and exclusion criteria designed for the present study. Institution Ethics Committee permission was obtained. Informed written consent was taken from all study participants if they were willing to participate in the present study after explaining the nature of the study in their local language.

\section{Inclusion criteria}

- Women found to have fibroids of size more than 10 $\mathrm{cm}$.

- Sixteen weeks pregnant uterine size.

- Multiple fibroid uterus varying from 5-15 cm.

\section{Exclusion criteria}

- Women with small fibroids.

- Not willing to participate in the present study.

\section{Methodology}

All the patients who underwent laparotomy and hysterectomy for large fibroids (measuring more than 10 $\mathrm{cm}$ or pregnant uterine size of 16 weeks or greater) were admitted at MRIMS during the study period were included in the present study.

Age varied from 25-42 years. 124 cases with myomas were reported out of which 32 cases were enrolled for this purpose. All the large fibroids had higher incidence of complications like menorrhagia, bladder symptoms like urinary retention, pain abdomen and heaviness of abdomen, bowel disturbances, abdominal lump, and vaginal discharge. Past history revealed that 10 of these patients had previous lower segment caesarian section and two had myomectomies.

Pre-operatively all patients were subjected to ultrasonography, abdomen / CECT abdomen and intra venous pyelography. Ureteric stenting was carried out in cervical fibroids and broad ligament fibroids. CECT was done to identify the site and size of the fibroid and adhesions and its relationship to ureter and bladder. Intra venous pyelography was done in all cases.

Five cases had hydronephrosis due to pressure over uterus. Pre-operative stenting was done in five cases. Preoperative blood counts, serology tests, coagulation and 
urine analysis were done in all cases. Infra umbilical vertical laparotomy was carried out in all cases. Foleys catheter was introduced to measure urine output in the patients. 31 cases were subjected to total abdominal hysterectomy. Subtotal hysterectomy was done in one case due to technical difficulty in delivering cervix.

The data was analyzed using proportions.

\section{RESULTS}

Majority of the study subjects were in the age group of 25-35 years. Only $21.9 \%$ were in the age group of 35-42 years. Thus, the incidence of large size uterine fibroids was more in younger age group.

Table 1: Age wise distribution of study subjects.

\begin{tabular}{|lll|}
\hline Age (years) & Number & $\%$ \\
\hline $25-35$ & 25 & 78.1 \\
\hline $35-42$ & 07 & 21.9 \\
\hline Total & 32 & 100 \\
\hline
\end{tabular}

The most common presenting symptom of large size fibroid uterus was abnormal uterine bleeding followed by pain abdomen in $18.8 \%$ of the cases.

Abdominal lump was seen in all cases. Urinary bladder disturbances were present in $15.6 \%$ of the cases and one fourth of the cases were having vaginal discharge.

Table 2: Distribution of study subjects as per the clinical features.

\begin{tabular}{|lll|}
\hline Clinical features & Number & $\%$ \\
\hline Abnormal uterine bleeding & 15 & 46.9 \\
\hline Pain abdomen & 06 & 18.8 \\
\hline Abdominal lump & 32 & 100 \\
\hline Urinary bladder disturbances & 05 & 15.6 \\
\hline Vaginal discharge & 08 & 25 \\
\hline
\end{tabular}

Majority of the women had fibroid size of 16-20 weeks in $62.5 \%$ of the cases followed by size of the 20-26 weeks in $31.3 \%$ of the cases. All women had palpable lump on abdominal examination in $100 \%$ of the cases.

Table 3: Distribution of study subjects as per the size of the uterine fibroid.

\begin{tabular}{|lll|}
\hline Size of the fibroid & Number & $\%$ \\
\hline $16-20$ weeks & 20 & 62.5 \\
\hline $20-26$ weeks & 10 & 31.3 \\
\hline $26-28$ weeks & 02 & 6.3 \\
\hline Total & 32 & 100 \\
\hline
\end{tabular}

Only three patients had intra operative complications $(9.4 \%)$. Among them two $(6.3 \%)$ had injury to the urinary bladder and only one had injury to the ureters. $90.6 \%$ of the cases had no intra operative complications.
Table 4: Distribution of study subjects as per the occurrence of intra operative complications.

\begin{tabular}{|c|c|c|}
\hline Intra operative complications & Number & $\%$ \\
\hline Injury to urinary bladder & 02 & 6.3 \\
\hline Injury to ureters & 01 & 3.1 \\
\hline Bowel injury & 00 & 00 \\
\hline No complications & 29 & 90.6 \\
\hline Total & 32 & 100 \\
\hline
\end{tabular}

All cases had complete symptomatic relief. Thus, the successful outcome was seen in $100 \%$ of the cases.

Table 5: Outcome of the laparotomy and hysterectomy in the present study.

$\begin{array}{lll}\text { Outcome } & \text { Number } & \% \\ \text { Symptomatic relief } & 32 & 100\end{array}$

\section{DISCUSSION}

All cases had complete symptomatic relief. Thus, the successful outcome was seen in $100 \%$ of the cases. Women with large size of the fibroid of the uterus are usually operated for hysterectomy using abdominal approach in majority of the cases. But for women who do not want to lose their uterus can be operated by method of myomectomy only. But in such cases, it has been found that the symptomatic relief may not be achieved in all cases. Hills $\mathrm{S}$ et al in their study found that the symptomatic relief was $80 \%$. In the present study authors found that the symptomatic relief was $100 \% .^{4}$

Iverson $\mathrm{R}$ et al in their study found that the blood loss on an average was $796 \mathrm{ml}$ two patients in their study developed ureteric injuries which is similar to the present study findings. ${ }^{5}$ There was one bladder injury which is also similar to the findings of the present study. There was one bowel injury, but authors had no case of bowel injury. In their study there were two cases of bowel obstructions among 89 study subjects who underwent abdominal hysterectomy.

Sawin $S$ et al found in their study that there was one case with injury to the ureter, one case with the injury to the bladder, three cases with the injuries to the bowel and five cases of wound dehiscence and six cases of pelvic abscesses among 197 women studied. ${ }^{6}$ In the present study authors had one case of wound dehiscence and there were no cases of pelvic abscesses.

Parket $\mathrm{W}$ et al reported that there was one case of bladder injury, two cases of bowel injuries, one case of wound dehiscence among the 91 cases they studied. ${ }^{7}$ In the present study authors found that bladder injuries cases were due to previous surgeries and dense adhesions, pathology may also contribute to bladder injury. In the case of sarcomatous degeneration authors had a case of bladder injury. 
Patient who had ureteric injury did not have pre-operative stenting. Although ureteric stenting was advised for patients with previous surgeries it has its own drawbacks like urinary tract infection, migration, stent fracture and erosions. $^{8-10}$ Hence it should be judiciously recommended.

Limitations to the study include lack of control group and small volume of patients. Authors believe that large uterine fibroids with previous history of abdominal surgeries do require laparotomy and hysterectomy.

\section{CONCLUSION}

Bladder injury was more frequent than ureteric injuries. If proper care is taken, bowel injuries can be avoided in the cases of large fibroids. In most large uterine fibroids symptomatic relief was greater with total abdominal hysterectomy.

Funding: No funding sources Conflict of interest: None declared

Ethical approval: The study was approved by the Institutional Ethics Committee

\section{REFERENCES}

1. Steiner FC. Hysterectomy rates in the United States 1990-1997. Obstet Gynecol. 2002;99:299-34.

2. Aronson MP, Bose TM. Urinary tract injury in pelvic surgery. Clin Obstet Gynecol. 2002;45:428-38.

3. Thompson JD. Operative injuries to the ureter; prevention, recognition and management. In: Rock JA, Thompson JD, eds. TeLinde's Operative Gynecology, 8th ed. Philadelphia; Lippincott Williams \& Wilkins; 1997:1135-1174.

4. Hills S, Marchbanks P, Peterson H. Uterine size and risk of complications among women undergoing abdominal hysterectomy for leiomyomas. Obstet Gynecol. 1996;87:539-43.

5. Iverson R, Chelmow D, Strohbehn K, Waldman L, Evantash E. Relative morbidity of abdominal hysterectomy and myomectomy for management of uterine leiomyomas. Obstet Gynecol. 1996;88:415-9.

6. Sawin S, Pilvesky N, BNerlin J, Barnbart K. Comparability of peri-operative morbidity between abdominal myomectomy and hysterectomy for women with uterine leiomyomas. Am J Obstet Gynecol. 2000;1448-55.

7. Parket W, Fu Y, Berek J. Uterine sarcoma in patients operated on for presumed leiomyomas and rapidly growing leiomyomas. Obstet Gynecol. 1994;83:4148 .

8. Ostrezenski A, Radolinskin B, Ostezenska KM. A review of laparoscopic Ureteral injury in pelvic surgery. Obstet Gynecol Surv. 2003;58(12):794-9.

9. Likic-Ladevic I, Kadija S, Ladevic N, Stefanovic A, Argirovic R, Petkovic S, et al. Urological complications after radical hysterectomy: incidence rates and predisposing factors. Vojnosanit Pregl. 2007;64(6):381-4.

10. Borboroglu PG, Amling CL, Schenkman NS, Monga M, Ward JF, Piper NY, et al. Ureteral stenting after ureteroscopy for distal ureteral calculi; a multiinstitutional prospective randomized controlled study assessing pain, outcomes and complications. J Urol. 2001;166(5):1651-7.

Cite this article as: Nalini YL, Chandra AS, Akshitha M. Prospective study of large uterine fibroids encountered during laparotomy and hysterectomy and their management. Int J Reprod Contracept Obstet Gynecol 2018;7:3601-4. 